\title{
FLACSO, CLACSO y la búsqueda de una sociología latinoamericana*
}

\section{Rodolfo Stavenhagen $^{* *}$}

\section{Resumen}

El texto es un aporte personal de la memoria del autor vinculada a algunos momentos que vivió en relación con el desarrollo de la Facultad Latinoamericana de Ciencias Sociales (FLACSO) y del Consejo Latinoamericano de Ciencias Sociales (CLACSO).

\begin{abstract}
Based on his personal memories, the author reflects on significant moments in the creation and development of the Facultad Latinoamericana de Ciencias Sociales (FLACSO) and the Consejo Latinoamericano de Ciencias Sociales (CLACSO).
\end{abstract}

Palabras clave: FLACSO, CLACSO, UNESCO, Ciencias Sociales, América Latina Key words: FLACSO, CLACSO, UNESCO, Social Sciences, Latin America

\footnotetext{
* Este texto fue leído en el evento conmemorativo del trigésimo octavo aniversario de la sede México de la Facultad Latinoamericana de Ciencias Sociales (FLACSO) celebrado el 30 de octubre de 2013. Es un aporte personal de mi memoria vinculada a algunos momentos que viví en relación con el desarrollo de FLACSO y CLACSO, y no pretende ser ni un estudio ni una evaluación de estas dos instituciones latinoamericanas.

** Rodolfo Stavenhagen, profesor-investigador emérito del Centro de Estudios Sociológicos de El Colegio de México, es doctor en sociología (1965) por la Universidad de París, Francia. Ha sido presidente de la Facultad Latinoamericana de Ciencias Sociales (FLACSO) y fue subdirector general para las ciencias sociales de la UNESCO. Entre 2001 y 2008 fue Relator Especial para los Derechos Humanos y Libertades Fundamentales de los Pueblos Indígenas, de la Organización de las Naciones Unidas. De su abundante producción destacamos Las Clases Sociales en las Sociedades Agrarias (1968), Derecho Indígena y Derechos humanos en América Latina (IIDH-El Colegio de México, 1988) y La cuestión étnica, El Colegio de México, 2001.
} 
el año de 1962 -hace más de medio siglo- asistí a una reunión del Comité Directivo de FLACSO en Río de Janeiro, junto con otros científicos sociales de Argentina, Brasil, Chile, Uruguay, Colombia y México, cuya representación la tenía Pablo González Casanova. Yo había llegado pocos meses antes a Río de Janeiro para asumir el cargo de Secretario General del Centro Latinoamericano de Investigaciones en Ciencias Sociales, cuyo director era el antropólogo brasileño Manuel Diégues Júnior. Allí pasé tres años antes de volver a México. Me tocó vivir el golpe de estado militar que derrocó al régimen democrático de Joao Goulart, el primero de una serie de golpes militares anti-democráticos en diversos países latinoamericanos, auspiciados por el gobierno de Estados Unidos.

El Centro formaba parte de la Facultad Latinoamericana de Ciencias Sociales, nuestra querida FLACSO, que fue creada por la UNESCO y los gobiernos latinoamericanos a raíz de una reunión regional latinoamericana, organizada por la UNESCO en 1957. En esta reunión los representantes de Brasil y de Chile ofrecieron sus países como sede de la nueva institución; al no poderse poner de acuerdo, llegaron a la solución salomónica de que Brasil sería la sede de un centro de investigaciones y Chile la sede del centro de docencia, la Escuela Latinoamericana de Sociología (ELAS), ambos cobijados bajo el manto de Facultad Latinoamericana de Ciencias Sociales. Fue cuando comenzaron los primeros problemas institucionales, porque la sana idea original era la de crear una sola institución que se dedicase tanto a la docencia como a la investigación. El Centro -como lo llamábamos brevemente--, situado en la bella bahía de Río de Janeiro, en el barrio de Praia Vermelha al pie del Pao de Azúcar, recibió apoyo del gobierno de Brasil para iniciar sus actividades, y la ELAS inició las suyas con el apoyo del gobierno en Santiago de Chile.

Cuando llegué a trabajar a Río los dos centros ya habían tomado rumbos distintos pero seguían unidos por el común comité directivo que respondía a las orientaciones de la UNESCO. Sólo algunos años después fueron adoptados nuevos estatutos y firmados nuevos acuerdos de sede.

Cuando volví a México después de la experiencia en Brasil -en la cual participé entre otras actividades en un estudio sobre estructura agraria y desarrollo agrícola auspiciado por el Comité Interamericano de Desarrollo Agrícola - me integré a El Colegio de México y formé un equipo de investigación que con el tiempo se constituiría en el Centro de Investigaciones Sociológicas -el CES - , formalizado en 1973. 
Debido, supongo, a mi experiencia en Sudamérica, fui invitado en 1965 a una conferencia regional de ciencias sociales en Bogotá, auspiciada también por la UNESCO, en la que se discutió ampliamente acerca de la creación del Consejo Latinoamericano de Ciencias Sociales (CLACSO), el cual fue fundado formalmente en 1967, y cuya sede fue establecida en Buenos Aires.

La creación de FLACSO y de CLACSO en la década de los cincuentassesentas del siglo pasado constituye un paso importante en la consolidación y el desarrollo de las ciencias sociales en la región latinoamericana y particularmente en algunos de los países de esta región. Este proceso no se da en un vacío, sino más bien responde a determinadas dinámicas internacionales y nacionales que se conjugan en esa época.

Como sabemos bien, las ciencias sociales y sus particulares disciplinas e instituciones tienen un proceso de incubación y evolución en los países latinoamericanos que las distingue de dinámicas semejantes en otras regiones. Para no ir más a fondo en la historia de las ideas, en nuestros países la época de la post-guerra (de la Segunda Guerra Mundial) tuvo particular relevancia, especialmente en el campo de la economía. Y para no ir más lejos, la tuvo en la conformación de nuestras dos instituciones (CLACSO y FLACSO) a través de su cercanía con el pensamiento innovador de la Comisión Económica de América Latina (CEPAL) de la Organización de las Naciones Unidas. La CEPAL (cuya sede latinoamericana se encuentra en Santiago de Chile) introdujo en el discurso político y académico el concepto del "desarrollo" desde fines de la década de los cuarentas, cuando en Europa aún se hablaba de la reconstrucción post-bélica. Para la adecuación de este concepto a las condiciones latinoamericanas algunos expertos de la CEPAL consideraron la utilidad de interactuar con diversos científicos sociales, entre ellos el sociólogo José Medina Echavarría, trasterrado de la guerra civil española, quien fundó el primer Centro de Estudios Sociales en El Colegio de México en los años cuarenta, y posteriormente fue el primer director de la Escuela Latinoamericana de Sociología (ELAS), de donde pasó precisamente a colaborar con la CEPAL. En esta institución de la ONU, como sabemos, el pensamiento innovador de Raúl Prebisch fue fundamental para reorientar el discurso de la economía política en América Latina, y desde el ILPES (Instituto Latinoamericano de Planificación Económica y Social), en donde laboraba José Medina Echavarría, emergen los estudios sobre la modernización y la dependencia, asidos al concepto de desarrollo económico y social, dos perspectivas fundamentales que orientaron el quehacer científico social latinoamericano durante varias décadas, con fuerte influencia en las investigaciones de FLACSO y CLACSO. 
Aunque pronto también se hizo sentir la influencia de la sociología y la ciencia política norteamericanas en los estudios de estas dos instituciones, un hilo conductor propiamente "latinoamericanista" acompañó sus actividades desde el principio. Si bien en distintas instituciones nacionales de ciencias sociales se realizaban trabajos importantes, en aquellos años la comunicación entre investigadores de distintos países de la región y de distintas disciplinas era escasa. Recuerdo que "descubrí" a mis colegas latinoamericanos durante los tres años que hice mis estudios de doctorado en la Universidad de Paris a principios de la década de los sesentas. CLACSO y FLACSO nacieron a la vida institucional con una vocación latinoamericanista que se ha ido reflejando en la composición de los grupos de trabajo y programas regionales de CLACSO y en la composición del profesorado y alumnado, así como en los programas académicos en las distintas sedes de FLACSO.

De esta manera, en diversos grupos de trabajo establecidos por CLACSO se pudieron organizar simposios y encuentros regionales y subregionales y producir investigaciones colaborativas y comparativas sobre temas de interés compartido que después de algunos años consolidaron una personalidad propiamente latinoamericana en el quehacer de diversas áreas del conocimiento. Como miembro del Comité Directivo de CLACSO durante algunos años me tocó fomentar la creación de los grupos de trabajo sobre estudios rurales y estudios laborales a los que se sumaron diversas instituciones e investigadores de varios países.

En los años de su creación, estas instituciones recibieron estímulos académicos y financieros de diversas fuentes, pero en ambas fue fundamental la contribución y la iniciativa de la UNESCO, el organismo de Naciones Unidas con responsabilidad universal. Cuando fui subdirector de la UNESCO para ciencias sociales a principios de la década de los ochenta, los dos programas seguían siendo tratados como modelos a seguir por la comunidad académica y diplomática internacional que se reúne en los majestuosos salones de aquella organización. Otras regiones solicitaban recibir la misma atención que la región latinoamericana, aunque los recursos disponibles habían disminuido ya considerablemente. En su ahora situación post-colonial los países africanos también querían establecer instituciones semejantes y pedían ayuda a quienes habían logrado construir el modelo latinoamericano de cooperación internacional en materia de ciencias sociales. Recuerdo dos conferencias internacionales en las que CLACSO desempeñó un papel importante, la primera en Dakar, Senegal, a principios de los setentas y la otra una década más tarde en El Cairo. En ambas reuniones se dieron animados debates entre científicos sociales africanos 
y latinoamericanos, se hablaba de desarrollo, de dependencia, del Tercer Mundo y de la liberación y autodeterminación de los países en estado post-colonial. Las ciencias sociales latinoamericanas ofrecían ya entonces perspectivas y orientaciones que fueron acogidas con interés y simpatía por nuestros colegas africanos.

Desde los años sesentas algunas fundaciones norteamericanas comenzaron a mostrar creciente interés en colaborar con nuestras instituciones. Este no era un interés inocente. La guerra fría había despertado en aquél país la necesidad de asumir lo que consideraba su responsabilidad planetaria y entre sus numerosas deficiencias se identificó el insuficiente conocimiento de los países y pueblos de las distintas regiones del mundo. Con el objetivo de suplir a estas deficiencias nacieron los diversos centros y programas universitarios de estudios de áreas (area studies centers) a los cuales el gobierno y varias fundaciones privadas norteamericanas asignaron importantes recursos. Nuestras instituciones latinoamericanas les cayeron como anillo al dedo por lo que pronto se vieron reflejados en donativos, programas conjuntos de investigación, becas de posgrado, publicaciones etc.

Los latinoamericanos supimos aprovechar la ocasión, y aunque podíamos no compartir con las fuentes norteamericanas su responsabilidad planetaria, los recursos no nos caían tan mal, y en nuestros consejos académicos se planteaba la necesidad de asumir profesionalmente el fondeo (fund-raising) necesario para convencer a los donantes que apoyarnos era una buena inversión. Pero también hubo incidentes mucho más serios como el que involucró al profesor noruego Johan Galtung de la FLACSO en Chile cuando le propusieron colaborar en una investigación, llamada Plan Camelot, promovida por el departamento de Defensa del gobierno de Estados Unidos, y que Galtung, cuando se dio cuenta, denunció ante la opinión pública con numerosos colegas chilenos.

Los tiempos iban cambiando, y en Latinoamérica se movían otras fuerzas más allá del desarrollo y la modernización. A raíz del golpe militar brasileño en 1964, unos años más tarde el Centro Latinoamericano de Investigaciones en Ciencias Sociales tuvo que cerrar sus puertas, y FLACSO quedó reducida a su centro docente en Chile, al que, con el apoyo del gobierno democrático, pronto pudo agregar la Escuela de Ciencias Políticas y extender sus actividades de investigación. Varios científicos sociales brasileños tuvieron que emigrar de su país, algunos como Fernando Henrique Cardoso, al ILPES en Santiago, antes de volver al Brasil para crear con ayuda de la Fundación Ford, el prestigioso centro de investigaciones CEBRAP (Centro Brasileiro de Análisis y Planeamiento), desde donde inició su carrera política que lo llevaría a la presidencia de la República. 
En esos años, pese al apoyo que recibía del gobierno chileno, FLACSO pasaba por situaciones difíciles de financiamiento. La ayuda programada de la UNESCO terminó en 1969, y FLACSO se mantuvo como resultado de un acuerdo intergubernamental con estatuto propio que en los primeros años sólo contaba con la firma de tres estados miembros: Chile, Cuba y Panamá. La herida más fuerte la recibió FLACSO con el golpe militar de Pinochet en Chile; dos de sus estudiantes bolivianos fueron asesinados por los golpistas y varios profesores e investigadores tuvieron que buscar el camino del exilio. Otros se quedaron pensando que como institución internacional, FLACSO podía servir de alguna manera de refugio. La Asamblea General de FLACSO, para ahorrar recursos, acostumbraba reunirse cada dos años en ocasión de la Conferencia General de la UNESCO en Paris, siendo sus miembros los representantes diplomáticos ante esta organización. En 1972 fui nombrado miembro de la delegación mexicana a la Conferencia General de la UNESCO y me tocó representar a mi país en la Asamblea de FLACSO. Fui electo presidente de esa reunión y de la institución, cargo en el cual había de durar casi quince años.

El golpe militar puso en peligro la supervivencia de la Facultad. El Consejo Superior no conocía las intenciones de la dictadura y algunos de sus miembros aconsejaban que se tomara la decisión de retirar la sede de Chile. Como en aquél entonces no había alternativa visible, esta propuesta resultaba a corto plazo impracticable y podía resultar en la desaparición de la FLACSO. Otra alternativa era acelerar la internacionalización de FLACSO como organismo regional, un proceso que se vislumbraba largo y complejo porque implicaba negociar la adhesión de otros países al acuerdo constitutivo de 1971. A nuestra reunión del Consejo Superior de 1974 asistió un representante del gobierno militar de Chile, un coronel de paracaidistas, corporación que había sido calificada como una de las más duras de aquél régimen. Tuvimos que explicarle lo que era un organismo internacional de ciencias sociales y por qué era conveniente abrir nuevas sedes y trasladar la Secretaría General a otro país, sin por ello tener que cerrar la sede académica en Santiago. El coronel reiteró el interés de su gobierno en mantener abierta y funcionando esta sede de FLACSO, ofreciendo garantías para su funcionamiento. Los colegas académicos de la sede me decían que esta era una manera de proteger a un núcleo de científicos sociales que querían quedarse en Chile. Finalmente me convencieron sus argumentos. 
Con todo, en 1975 fue abierta, un poco al vapor, una subsede en Buenos Aires para la Secretaría General, a cargo de Arturo O'Connell. Aunque temporalmente se había salvado la situación, era preciso consolidar a FLACSO en el largo plazo. Gonzalo Abad, representante de Ecuador, ofreció la posibilidad de abrir una sede académica en su país. Aquí en México me puse a trabajar y con el apoyo de Víctor Urquidi, presidente de El Colegio de México (Colmex), tuve una primera larga entrevista con el Secretario de Educación Pública, Víctor Bravo Ahuja, quien había apoyado pocos años antes la creación del Centro de Estudios Sociológicos en el Colmex. El Secretario de Educación consultó al presidente Luis Echeverría y en uno de esos encuentros masivos a los que el presidente era aficionado, me empujó hasta que de repente me encontré frente a frente con Echeverría mientras Bravo Ahuja me susurraba "háblele, háblele". Fue cuando en un espacio de no más de tres minutos le planteé al presidente Echeverría el drama de una institución tan prestigiosa como la nuestra, al tiempo que le dejaba ver lo bueno que sería para México ofrecer nuestra hospitalidad a los intelectuales sudamericanos perseguidos y exiliados. El presidente inclinaba la cabeza con atención y me dio a entender que se ocuparía del asunto. Al poco tiempo le hice llegar un expediente con los principales datos y, para mi agradable sorpresa, algunos días más tarde recibí una llamada telefónica de su secretaria particular indicándome que la Secretaría de Educación ya había recibido las instrucciones correspondientes. De esta manera FLACSO pudo echar raíces en este país. Meses después, cambio de régimen de por medio, el nuevo presidente José López Portillo, acompañado de su Secretario de Educación Porfirio Muñoz Ledo, también amigo de FLACSO, inauguró este edificio en el cual nos encontramos ahora. En el interim, México había firmado el nuevo acuerdo de la FLACSO, contribuyendo así al proceso de descentralización ya anunciado.

Quedaba por resolver el problema de la Secretaría General. El buen colega Daniel Camacho, representante de Costa Rica en el Consejo Superior, y reconocido científico social en su país, puso manos a la obra con su gobierno. En ocasión de una reunión del Consejo en San José tuve una larga y amable conversación con el presidente Rodrigo Carazo quien luego dio instrucciones para que Costa Rica ofreciera ser sede de la Secretaría General. Este ofrecimiento fue aceptado por el Consejo en 1979, al tiempo que Daniel Camacho fue elegido como nuevo Secretario General de la institución. Como señala el historiador Héctor Pérez Brignoli, “el aspecto 
más significativo de la reforma fue el convertir a la Secretaría General en una instancia de coordinación, dejando amplia autonomía a las Sedes."

En los países del Cono Sur las ciencias sociales - junto con otras disciplinas - fueron muy golpeadas por las dictaduras militares: centros de investigación y docencia clausurados; académicos y estudiantes encarcelados, expulsados o desaparecidos; funcionarios perseguidos etc. Ante la emergencia, el Secretario Ejecutivo de CLACSO, Enrique Oteiza, lanzó un programa de reubicación de cientistas sociales, incluyendo una Bolsa de Trabajo para estudiantes y profesores, para el cual logró conseguir amplio apoyo internacional. La rapidez e intensidad con la que se movilizó la comunidad de científicos sociales en América Latina, América del Norte y algunos países europeos, recuerda la movilización internacional que durante la segunda guerra mundial logró salvar la vida a numerosos perseguidos, refugiados y exiliados de los países bajo regímenes fascistas. Un ejemplo más de solidaridad latinoamericana en acción.

Los regímenes militares que asolaron el continente latinoamericano en la segunda mitad del siglo veinte dieron lugar a un giro importante en las prioridades y orientaciones de las ciencias sociales en la región. Éstas comenzaron a ocuparse más de los sistemas y movimientos políticos, de la naturaleza del Estado y sus instituciones y del anhelado retorno a la democracia. Ya no solamente la sociología y la economía, sino también la ciencia política, aportaron importantes e innovadores análisis y reflexiones. Nuevamente se advierte un sesgo "latinoamericanista" al que contribuyeron ambas instituciones aquí reseñadas, así como numerosos centros de estudio nacionales y extranjeros que participaban y participan en las redes construidas en torno a FLACSO y CLACSO. El desarrollismo vinculado a los planteamientos de la CEPAL quedó relegado.

Sin pretender hacer un análisis más cuidadoso, no debemos olvidar que las ciencias sociales presentan diferentes enfoques teóricos. Así sucede también con la producción académica de nuestras dos instituciones. A lo largo del último medio siglo nuestra producción intelectual también refleja distintas modas analíticas y metodológicas sin apartarse por ello de la preocupación central de ampliar nuestra comprensión de los fenómenos latinoamericanos. Por ejemplo, tanto en relación con la problemática del desarrollo y la modernización, como la del Estado, la política y la democracia, podemos detectar enfoques neoliberales, neoconservadores, neomarxistas, postmodernistas y otros planteamientos. El encuentro de estas corrientes ha dado lugar a encendidos debates y polémicas, como lo 
atestiguan las publicaciones y las tesis de FLACSO y CLACSO a lo largo de los últimos años.

Si bien el Consejo Superior de FLACSO no es una palestra académica, en numerosas ocasiones, a lo largo de los años que me tocó colaborar, los miembros del Consejo tuvimos la buena suerte de intercambiar informaciones y opiniones con los distintos directores de sedes y de programas especiales. Recuerdo interesantes conversaciones con Darcy Ribeiro del Brasil, José Joaquín Brunner de Chile, Gino Germani de Argentina y otros.

En años más recientes se ha dado un nuevo giro en la narrativa de lo latinoamericano que es asumido en las publicaciones y trabajos de las dos instituciones que nos ocupan. Me refiero al énfasis en lo cultural y a los enfoques más subjetivos. Hoy se habla menos de la "realidad social latinoamericana" como un concepto que tuviera existencia propia sin la intervención de los científicos sociales. En este enfoque destacan las preocupaciones en torno a la cuestión de género, las relaciones raciales e interétnicas y las identidades culturales de pueblos indígenas y afro-americanos. En la etapa post-democratización surgen con más intensidad las críticas a los procesos democráticos, los problemas de las políticas sociales, los derechos humanos, el sentido de pertenencia, y temas afines. Al mismo tiempo que FLACSO y CLACSO recobraron su institucionalidad en el mundo académico, resulta cada vez más cuestionada la idea de una "ciencia social latinoamericana" en un mundo globalizado y multipolar. Ya no hay guerra fría, pero ahora existen múltiples niveles de violencia, enriquecidos por fabulosas tecnologías de espionaje universal. El mercado financiero es global, pero los migrantes sin papeles que desean cruzar alguna frontera o playa son más vulnerables y miserables que nunca antes.

Ante estas circunstancias, diversas instituciones y organizaciones académicas como CLACSO y ALAS (Asociación Latinoamericana de Sociología) continúan activamente construyendo las ciencias sociales latinoamericanas desde sus particulares perspectivas. CLACSO, por ejemplo, utiliza amplia e inteligentemente los medios de comunicación masiva como internet y las redes sociales para fortalecer el conocimiento de América Latina así como la cooperación académica dentro y fuera del área. La página web de CLACSO es un nódulo indispensable para estudiantes y estudiosos de todas las latitudes. Nos informa el equipo CLACSO:

Con el objeto de dar visibilidad y facilitar el acceso a los resultados de las investigaciones de los Centros Miembros de CLACSO, hemos desarrollado a partir de 1998 un repositorio institucional que ofrece actualmente acceso abierto y gratuito a: 
Sala de Lectura con textos completos de libros, revistas no arbitradas, ponencias y documentos de trabajo publicados por la red CLACSO

Portal de Revistas arbitradas (con revisión por pares) de la Red CLACSO es un servicio conjunto CLACSO - Redalyc

Portal Multimedia, que incluye enlaces a producciones audiovisuales, radios en línea, archivos de audio y colecciones fotográficas de la red CLACSO

Buscador Personalizado de la red CLACSO (busca en los sitios web de los centros miembros y programas de CLACSO)

CLACSO, en colaboración con más de 300 centros miembros en 20 países de América Latina y el Caribe, participan en la promoción del acceso abierto a los resultados de investigaciones financiadas con fondos públicos. La Campaña CLACSO de Apoyo al Acceso Abierto al Conocimiento Académico y Científico refleja actividades realizadas por CLACSO y sus centros miembros en toda la región.

Por lo demás, El Observatorio Social de América Latina (OSAL) es un programa de investigación iniciado en el año 2000, orientado a promover y divulgar elementos para un análisis crítico del capitalismo latinoamericano, los procesos políticos, sociales y económicos emergentes y las diversas formas que asume el conflicto y los movimientos sociales en la región (www.clacso.org.ar).

En este aniversario de la fundación de la sede en México de FLACSO, nos podemos preguntar: ¿Existe la necesidad o la posibilidad o la conveniencia de seguir buscando o construyendo una ciencia social propia de América Latina?

La respuesta la tienen ustedes. Muchas gracias. 


\section{Bibliografía}

Consejo Latinoamericano de Ciencias Sociales (CLACSO), boletines editoriales diversos, biblioteca virtual y página web (www.clacso.org.ar)

Rolando Franco, 2007, La FLACSO clásica (1957-1973), Santiago de Chile, FLACSO.

Edmundo Fuenzalida Faivovich, 2007, La primera FLACSO (1957-1966): cooperación internacional para la actualización de la sociología en América Latina, Serie Recuerdos de la FLACSO, Santiago de Chile, FLACSO.

Manuel Antonio Garretón y Hernán Pozo, 1984, Las universidades chilenas y los derechos humanos, Documento de Trabajo, Santiago de Chile, FLACSO.

Francis J. Manno \& Richard Bednarcik, 1968, "El proyecto Camelot", Foro Internacional, IX-2, pp. 206-218.

Juan Jesús Morales, 2012, “De los aspectos sociales del desarrollo económico a la teoría de la dependencia: sobre la gestación de un pensamiento social propio en Latinoamérica", Cinta de Moebio 45, pp. 235-252.

Diego Pereyra, compilador, 2010, El desarrollo de las ciencias sociales. Tradiciones, actores e instituciones en Argentina, Chile, México y Centroamérica, San José, Costa Rica, FLACSO.

Héctor Pérez Brignoli, 2008, Los 50 años de la FLACSO y el desarrollo de las ciencias sociales en América Latina, San José, Costa Rica, Editorial Juricentro, FLACSO Secretaría General.

José Luis Reyna, 2004, “La institucionalización y profesionalización de las ciencias sociales en América Latina", Estudios Sociológicos, XXII: 65, pp. 483-493.

Marcos Roitman Rosenmann, 2008, Pensar América Latina: el desarrollo de la sociología latinoamericana, Buenos Aires, CLACSO.

Recibido el 25 de octubre de 2013 Aceptado el 25 de noviembre de 2013 